\title{
Subclavian and axillary vessel anatomy: a prospective observational ultrasound study
}

\section{Anatomie vasculaire sous-clavière et axillaire : une étude échographique observationnelle prospective}

\author{
Catherine Lavallée, MDCM • Christian Ayoub, MD, BPharm - Asmaa Mansour, MSc • \\ Jean Lambert, PhD · Jean-Sébastien Lebon, MD, BPharm • Manoj M. Lalu, MD, PhD • \\ André Denault, MD, PhD
}

Received: 27 March 2017/Revised: 23 October 2017/Accepted: 29 October 2017/Published online: 5 December 2017

(C) Canadian Anesthesiologists' Society 2017

\begin{abstract}
Purpose The primary objective of this study was to define the ultrasound-derived anatomy of the axillary/subclavian vessels. As a secondary objective, we evaluated the relationship between the vascular anatomy and demographic, anthropometric, and hemodynamic data of patients.

Methods This observational anatomical study used bedside ultrasound with 150 cardiac surgical patients in the operating room. Bilateral axillary and subclavian anatomy was determined using a high-frequency ultrasound probe with fixed reference points. Images were recorded and analyzed, and correlation with demographic, anthropometric, and hemodynamic data was performed.
\end{abstract}

Results The images were adequate to evaluate potential anatomical variations in $97.4 \%$ of patients with a body

C. Lavallée, MDCM · C. Ayoub, MD, BPharm .

J.-S. Lebon, MD, BPharm · A. Denault, MD, PhD ( $ه)$

Department of Anesthesiology, Montreal Heart Institute,

Université de Montréal, 5000 Belanger Street, Montreal,

QC H1T 1C8, Canada

e-mail: andre.denault@umontreal.ca

A. Mansour, MSc

Health Innovations Coordinating Center (MHICC), Montreal

Heart Institute, Montreal, QC, Canada

J. Lambert, $\mathrm{PhD}$

Department of Preventive and Social Medicine, Université de Montréal, Montreal, QC, Canada

M. M. Lalu, MD, $\mathrm{PhD}$

Department of Anesthesiology, The Ottawa Hospital, Ottawa

Hospital Research Institute, Ottawa, ON, Canada mass index as high as $46.4 \mathrm{~kg} \cdot \mathrm{m}^{-2}$. The mean (standard deviation) diameter of the axillary vein was $1.2(0.3) \mathrm{cm}$ on the right side and $1.1(0.2) \mathrm{cm}$ on the left side. The dimensions of the axillary vein were larger on the right side in $69 \%$ of patients. The vein was located directly over the artery in the mid-clavicular view in $67 \%$ of the patients and in lateral-clavicular view in only $7 \%$ of the patients. As we moved the probe laterally, the vein was lateralized in relation to the artery in $89 \%$ of patients. There was no significant correlation between the hemodynamic data and vessel size, although direct correlation was found between body mass index and the depth of the vessel $(P<0.001)$. The axillary vein area was smaller in females than in males $(P<0.002)$, and in $4 \%$ of patients, the axillary vein was in an aberrant position.

Conclusions In patients undergoing cardiac surgery, axillary vessel anatomy varied considerably, and the patients' hemodynamics could not predict the size of the axillary vessels. Only the patients' weight correlated moderately with the depth of the vein.

\section{Résumé}

Objectif L'objectif principal de cette étude était de définir l'anatomie dérivée de l'échographie des vaisseaux axillaires et sous-claviers. Comme objectif secondaire, nous avons évalué la relation entre l'anatomie vasculaire et toutes les données démographiques, anthropométriques et hémodynamiques des patients.

Méthode Cette étude anatomique observationnelle réalisée en utilisant léchographie de surface au chevet de 150 patients de chirurgie cardiaque en salle d'opération. L'anatomie axillaire et sous-clavière bilatérale a été déterminée à l'aide d'une sonde d'échographie à haute fréquence selon des points de 
référence fixes. Les images ont été enregistrées et analysées, et nous avons réalisé des analyses de corrélation avec les données démographiques, anthropométriques et hémodynamiques.

Résultats Les images étaient adéquates pour évaluer les variations anatomiques chez 97,4\% des patients ayant un indice de masse corporelle allant jusqu'à $46,4 \mathrm{~kg} \cdot \mathrm{m}^{-2}$. Le diamètre moyen (écart type) de la veine axillaire était de $1,2(0,3)$ cm sur le côté droit et de $1,1(0,2)$ cm sur le côté gauche. Les dimensions de la veine axillaire étaient plus grandes sur le côté droit chez $69 \%$ des patients La veine était située directement au-dessus de l'artère en vue position claviculaire médiane chez $67 \%$ des patients et dans la portion claviculaire latérale chez seulement $7 \%$ des patients. Lorsque la sonde a été déplacée latéralement, la veine était latéralisée par rapport à l'artère chez $89 \%$ des patients. Aucune corrélation significative n'a été observée entre les données hémodynamiques et la taille des vaisseaux, bien qu'une corrélation directe ait été observée entre l'indice de masse corporelle et la profondeur $d u$ vaisseau $(P<0,001)$. L'aire de la veine axillaire était plus petite chez les femmes que chez les hommes $(P<0,002)$. Chez $4 \%$ des patients, la veine axillaire était dans une position aberrante.

Conclusion Chez les patients subissant une chirurgie cardiaque, l'anatomie vasculaire axillaire varie grandement, et il n'était pas possible de prédire la taille des vaisseaux axillaires à l'aide des données hémodynamiques. Seul le poids des patients était modérément corrélé à la profondeur de la veine.

Ultrasound (US) is a powerful tool that allows clinicians to perform invasive techniques more safely, including central venous cannulation. Indeed, for more than a decade, USguided central venous cannulation has gained recognition for its ability to reduce failed attempts and complication rates. ${ }^{1-3}$ A number of international agencies recommend its utility as standard of care, including the United Kingdom National Institute for Health and Care Excellence. ${ }^{4}$ Nevertheless, the majority of studies on US-guided vascular access focus on the internal jugular vein. 5,6

A recent randomized trial has shown that the use of US for subclavian vein access is superior to the landmark technique. ${ }^{3}$ This advantage is further supported by a recent systematic review and meta-analysis which demonstrated that the use of dynamic two-dimensional US reduces both the number of failed attempts and the complication rate. ${ }^{7}$ Despite these potential benefits and recent reports of high success rates in experienced hands, ${ }^{8}$ the use of echo-guided subclavian vein cannulation is relatively low.
Subclavian cannulation is more difficult than cannulation of the internal jugular vein, in part because of the proximity of the pleural space and it being a deeper target which increases the risk of pneumothorax. ${ }^{9}$ This potential difficulty with subclavian vein cannulation techniques could be secondary to the relationships between its anatomical variations and the surrounding structures. Thus far, few studies have explored the anatomical variations encountered using US-guided subclavian or axillary vessel cannulation. ${ }^{10,11}$ In addition, descriptions are lacking regarding the relationship between cardiac filling pressures and the anatomical dimensions of the axillary and subclavian vessels, although descriptions do exist regarding the internal jugular vein. ${ }^{12}$

In this prospective observational study, we examined the anatomical characteristics of the subclavian and axillary vessels in patients undergoing surgical intervention requiring central venous cannulation. As a secondary objective, we evaluated the correlation between vessel morphology and both patient characteristics and cardiac filling pressures.

\section{Method}

The Montreal Heart Institute Research and Ethics Committee approved this study (\#10-1197, November 2011) and waived the need for patient consent due to the observational and non-interventional nature of the project. This study is reported in accordance with the STROBE guidelines. ${ }^{13}$ One hundred fifty patients were studied from August to November 2010. These patients were scheduled for elective cardiac surgery where US-guided vascular access is routinely used. Age, sex, weight, height, body mass index (BMI), body surface area, and surgical procedure were recorded for each patient (Table 1).

Table 1 Demographic data

\begin{tabular}{ll}
\hline Data & Information gathered \\
\hline Patients $(n)$ & 150 \\
Gender & \\
$\quad$ Male & $106(71 \%)$ \\
Female & $44(29 \%)$ \\
Age yr, mean (SD) & $67(10)$ \\
Height m, mean (SD) & $1.66(0.9)$ \\
Weight kg, mean $(\mathrm{SD})$ & $79(15)$ \\
Body mass index kg.m ${ }^{-2}$, mean $(\mathrm{SD})$ & $28.6(5.6)$ \\
Race & \\
Caucasian & $148(98.6 \%)$ \\
Other & $2(1.4 \%)$ \\
\hline
\end{tabular}

$\mathrm{SD}=$ standard deviation 


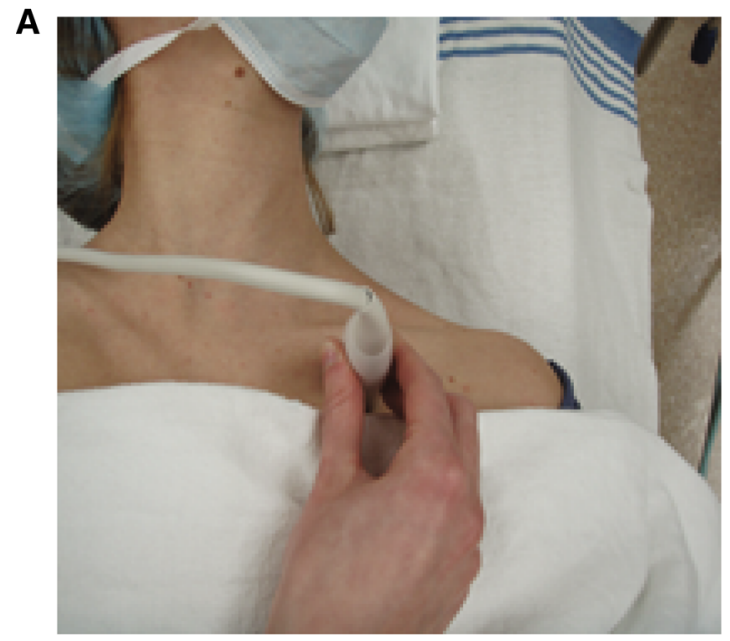

C

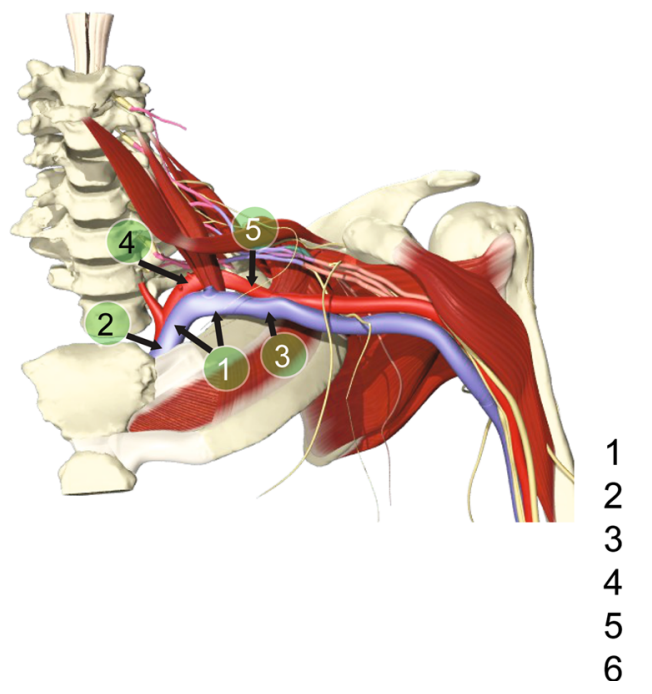

Fig. 1 A) Subclavian and axillary vein anatomy. Position of the probe on the axillary vessels with the typical B) two-dimensional image. $C, D)$ The axillary vein becomes the subclavian vein under the subclavius muscle and the clavicle. Reproduced with permission

The patients were premedicated one hour prior to surgery with intramuscular morphine $0.05-0.1 \mathrm{mg} \cdot \mathrm{kg}^{-1}$ and midazolam $0.02-0.05 \mathrm{mg} \cdot \mathrm{kg}^{-1}$. Induction of anesthesia was achieved with midazolam $0.04 \mathrm{mg} \cdot \mathrm{kg}^{-1}$ and sufentanil $1 \mu \mathrm{g} \cdot \mathrm{kg}^{-1}$ (or fentanyl $10 \mu \mathrm{g} \cdot \mathrm{kg}^{-1}$ according to the anesthesiologist's preference), and muscle relaxation was achieved with rocuronium $1 \mathrm{mg} \cdot \mathrm{kg}^{-1}$. For anesthesia maintenance, sufentanil $1 \mu \mathrm{g} \cdot \mathrm{kg}^{-1} \cdot \mathrm{hr}^{-1}$ (or fentanyl $10 \mu \mathrm{g} \cdot \mathrm{kg}^{-1} \cdot \mathrm{hr}^{-1}$ ), midazolam $\quad 0.01-0.05 \mathrm{mg} \cdot \mathrm{kg}^{-1} \cdot \mathrm{hr}^{-1}$, and isoflurane $0.5-1.5 \%$ end-tidal concentration were used. Ventilation was adjusted to maintain end-tidal carbon dioxide at $30-40 \mathrm{mmHg}$. Following the induction of anesthesia, the patients were positioned in order to facilitate vascular puncture. A small rolled towel was

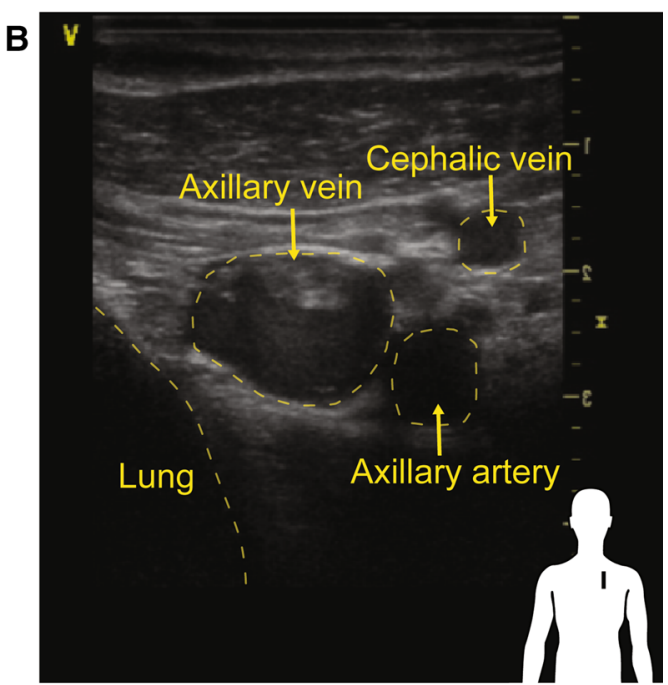

D

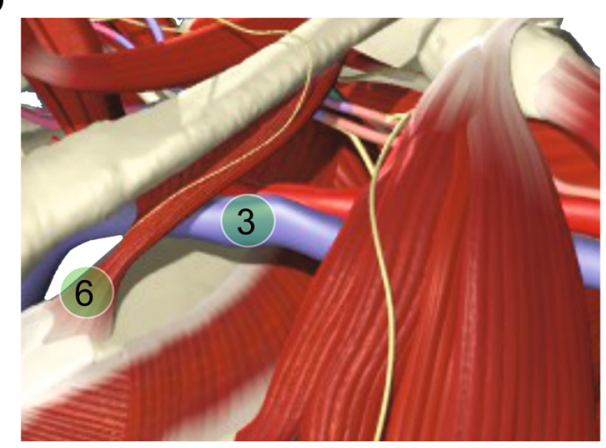

\section{Subclavian vein \\ Brachiocephalic vein \\ Axillary vein \\ Subclavian artery \\ Axillary artery \\ Subclavius muscle}

from: Denault AY, Vegas A, Lamarche Y, Tardif JC, Couture P. Basic Transesophageal and Critical Care Ultrasonography. London: CRC Press; $2017^{22}$

placed beneath the patients' shoulders, and their arms were tucked alongside their body, while the head was kept in a neutral position. The operating room table also remained in a neutral position. A high-frequency $10 \mathrm{MHz}$ linear array probe (Vivid 7 imaging; GE Healthcare, Amersham, Sweden) was used to obtain the two-dimensional images of the subclavian/axillary vessels prior to central venous catheterization (Fig. 1A and B).

The axillary vein starts at the inferior border of the teres major muscle and becomes the subclavian vein at the lateral border of the first rib under the subclavius muscle (Fig. 1C and D). ${ }^{3,4}$ Therefore, in the majority of patients undergoing US-guided "subclavian" vascular access, the axillary vein is cannulated more often than the actual 
Fig. 2 A) Schematic description of the left midclavicular and left lateralclavicular position of the ultrasound probe. B) Schematic description of the position of the vein $(\mathrm{V})$ with regard to the artery. Numbers 1-5 are related to the position of the vein in relation to the artery (A). Anterior position corresponds to 1 and 2; medial position corresponds to 3 and 4; position 5 refers to a vein positioned medially and under the artery
A
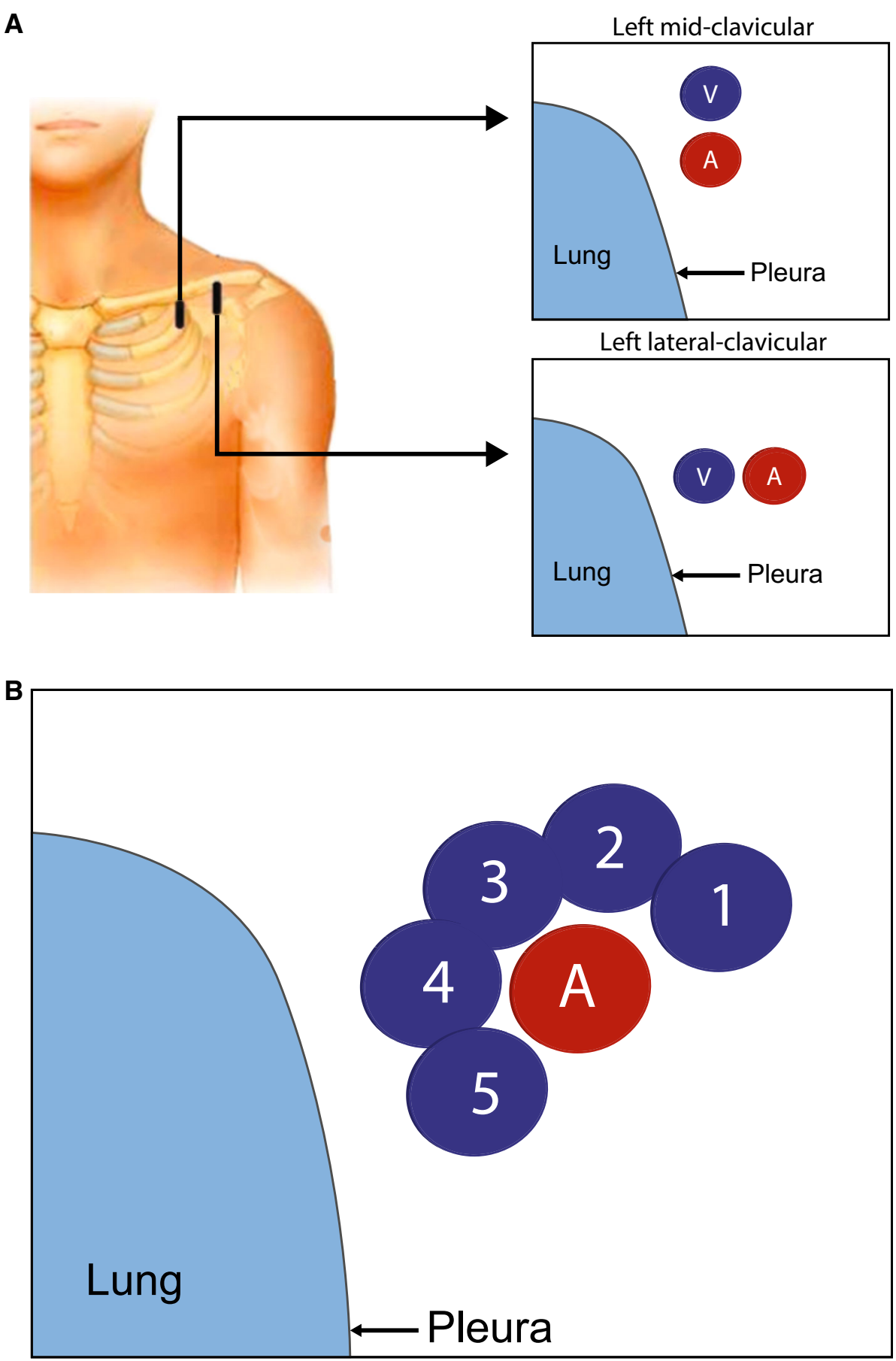

subclavian vein. Minimal pressure was applied on the probe to obtain the images in order to prevent distortion. The probe was always positioned at a $90^{\circ}$ angle (i.e., perpendicular) to the table and parallel to the patient's midline (i.e., sagittal). A typical image is shown in Fig. 1B. As the vessels became slightly oblique once the probe moved toward the upper arm, we rotated the probe slightly clockwise in the more lateral points of measurement to obtain the most circular aspect of the vessels.
Measurements were obtained at the end of expiration. A single operator acquired all the images.

The orientation of the acquired images was based on conventional cardiology landmarks where the right side of the image corresponds to the upper portion of the body. Four different images were acquired-i.e., on both the left and right side and at two locations relative to the clavicle (which was divided into two parts - mid-clavicular image below the mid portion of the clavicle and the lateral- 
A

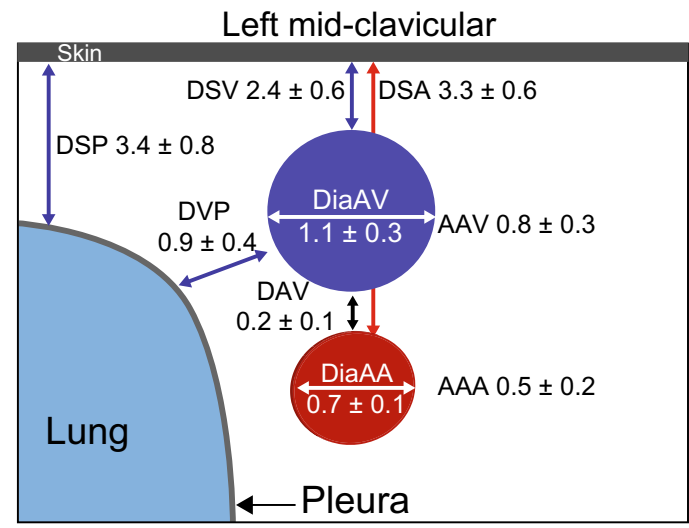

C

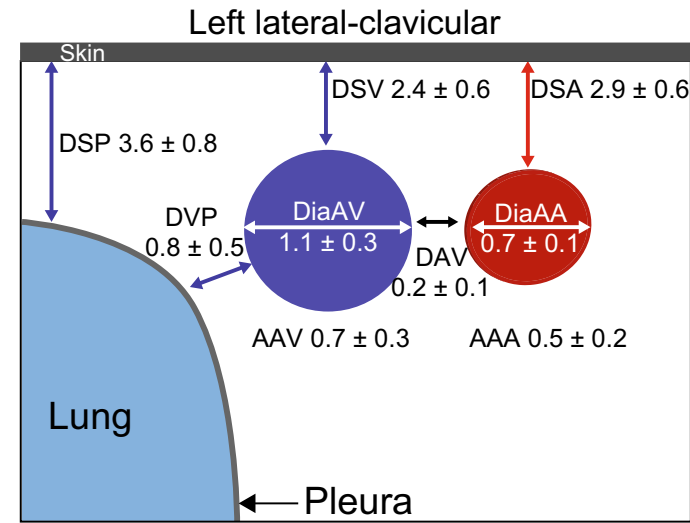

Fig. 3 A) Measurement summary of the right mid-clavicular position; B) the right lateral-clavicular position; C) the left midclavicular position; and D) the left lateral-clavicular position. All measurements are in centimetres, except for the cross-sectional areas which are in $\mathrm{cm}^{2} . \mathrm{AAA}=$ area axillary artery; $\mathrm{AAV}=$ area axillary

clavicular image at the lateral quarter of the clavicle) (Fig. 2A). The position of the vein in relationship to the artery was noted according to a pre-established diagram (Fig. 2B). At each of the mid- and lateral-clavicular locations, nine measurements were obtained, including vessel diameter, vessel cross-sectional area, distance between the skin and the anterior surface of the axillary artery and vein, the distance between the axillary artery and vein (i.e., arteriovenous distance), distance between the closest portion of the vein and the pleura (i.e., venopleural distance), and the distance from the pleura to the skin. The vessel cross-sectional area was not measured if $<80 \%$ of the contour could be traced based on the Schnittger criteria. $^{14}$

After obtaining the images, a thermodilution pulmonary artery catheter (7.5F 931HF75, Baxter Healthcare, Irvine, CA, USA) was inserted, and a complete hemodynamic profile was performed within ten minutes prior to surgical incision (as is routinely done at our institution). Measured variables included heart rate, systolic and diastolic arterial pressure, systolic and diastolic pulmonary artery pressure
B

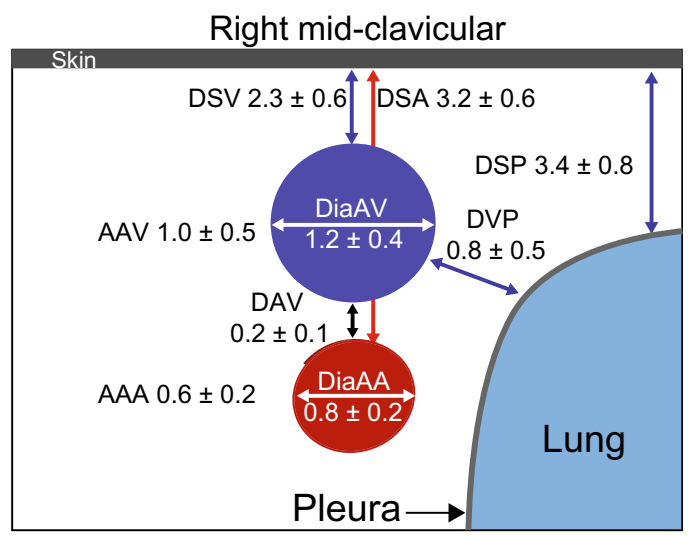

D

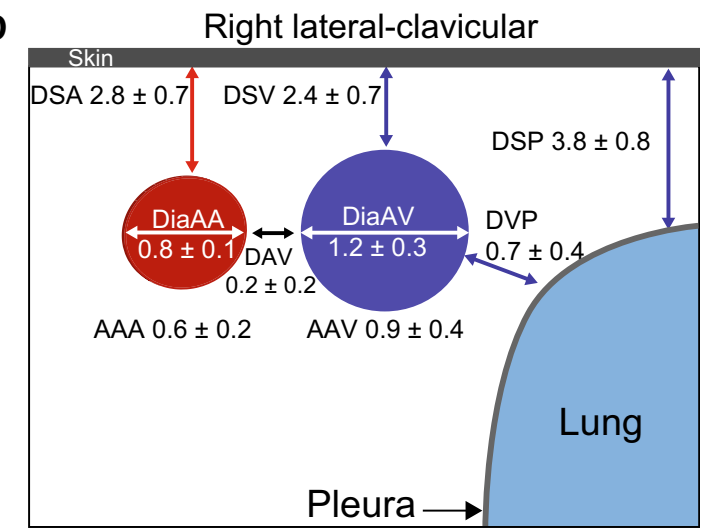

vein; DiaAA $=$ diameter axillary artery; DiaAV $=$ diameter axillary vein; $\mathrm{DAV}=$ distance between the artery and vein; $\mathrm{DSA}=$ distance between skin and artery; DSP = distance between the skin and the pleura; DSV = distance from the skin to the vein; DVP $=$ distance between the vein and the pleura

(PAP), as well as central venous pressure (CVP), and pulmonary capillary wedge pressure.

Statistical analysis

Descriptive statistics were performed on patients' characteristics. Mean (standard deviation [SD]) and median [interquartile range (IQR)] were presented for continuous variables, whereas counts and proportions were presented for all categorical variables. ${ }^{15}$ Comparisons between subgroups (i.e., right $v s$ left and mid-clavicular $v s$ lateral-clavicular) were performed using Student's $t$ test or Mann-Whitney test following normality assumption check using the Kolmogorov-Smirnov testing. A forward multiple stepwise regression approach was used to identify any relationship between patients' demographics (i.e., age, sex, height, weight, BMI), patients' hemodynamic filling pressures, and the vessel cross-sectional area and depth. The significance levels were set at $P<0.01$ for inclusion of a predictor in the model. In considering what to include in the model's basic variables, patients' demographics were 
Table 2 Ultrasound-based measurements

\begin{tabular}{|c|c|c|c|c|}
\hline & \multicolumn{2}{|c|}{ Mid-clavicular } & \multicolumn{2}{|c|}{ Lateral-clavicular } \\
\hline & Left & Right & Left & Right \\
\hline AAA & $0.5(0.2)$ & $0.6(0.2)$ & $0.5(0.2)$ & $0.6(0.2)$ \\
\hline AAV & $0.8(0.3)$ & $1.0(0.5)$ & $0.7(0.3)$ & $0.9(0.4)$ \\
\hline DAV & $0.2(0.1)$ & $0.2(0.1)$ & $0.2(0.1)$ & $0.2(0.2)$ \\
\hline DSA & $3.3(0.6)$ & $3.2(0.6)$ & $2.9(0.6)$ & $2.8(0.7)$ \\
\hline DSP & $3.4(0.8)$ & $3.4(0.8)$ & $3.6(0.8)$ & $3.8(0.8)$ \\
\hline DSV & $2.4(0.6)$ & $2.3(0.6)$ & $2.4(0.6)$ & $2.4(0.7)$ \\
\hline DVP & $0.9(0.4)$ & $0.8(0.5)$ & $0.8(0.5)$ & $0.7(0.4)$ \\
\hline DiaAV & $1.1(0.3)$ & $1.2(0.4)$ & $1.1(0.3)$ & $1.2(0.3)$ \\
\hline DiaAA & $0.7(0.1)$ & $0.8(0.2)$ & $0.7(0.1)$ & $0.8(0.1)$ \\
\hline
\end{tabular}

Data are expressed as mean (standard deviation). Distance/diameter measurements are in centimetres. Area measurements are in $\mathrm{cm}^{2}$

$\mathrm{AAA}=$ area axillary artery; AAV = area axillary vein; DAV = distance between the artery and vein; DiaAA = diameter axillary artery; DiaAV = diameter axillary vein; DSA $=$ distance between skin and artery; DSP $=$ distance between the skin and the pleura; DSV $=$ distance from the skin to the vein; DVP = distance between the vein and the pleura

considered first, followed by hemodynamic filling pressures. At each step, the nature of the relationship (e.g., linear, quadratic) was verified and modifications were performed when necessary.

Our sample size calculation was based on a study by Galloway that provided estimates of axillary vein depth. ${ }^{10}$ Based on this study, it was assumed that the SD of the axillary vein depth would be $0.5 \mathrm{~cm}$. Under this assumption, a sample size of 150 patients would allow for the estimation of the mean axillary vein depth with an SD precision of $0.08 \mathrm{~cm}$ using a $95 \%$ confidence interval. In general, this sample size allows for the estimation of a mean with an SD precision of $0.16 \mathrm{~cm}$. In addition, for the second objective of evaluating correlations between vessel morphology and other characteristics, a sample size of 150 allows for the detection of a correlation of 0.225 with a power of $80 \%$ and a significance level of 0.05 . The statistical analysis was performed using SAS ${ }^{\circledR}$ version 9.2 or later (SAS Institute Inc., Cary, NC, USA).

\section{Results}

One hundred fifty patients (106 males; 44 females) aged 25-88 yr were examined. Their mean (SD) age and BMI were 67 (10) $\mathrm{yr}$ and $28.6(5.1) \mathrm{kg} \cdot \mathrm{m}^{-2}$, respectively (Table 1). One hundred sixty-five $(3 \%)$ of the 5,400 possible two-dimensional images could not be obtained; $76(46 \%)$ of the missing measurements were arterial crosssectional areas or other dimensions. The measurements are summarized in Fig. 3 and Table 2.
Venous and arterial anatomy at the mid- and lateralclavicular region

At the mid-clavicular location, the mean (SD) of the right axillary vein diameter was $1.2(0.4) \mathrm{cm}$ on the right side and $1.1(0.3) \mathrm{cm}$ on the left side. It was similar in the lateral region, but in $96(64 \%)$ patients, the vein was larger at the mid-clavicular view and became smaller laterally. In the lateral-clavicular position, the vein diameter was $\leq 1.0 \mathrm{~cm}$ in $33(22 \%)$ patients on the right side and $49(33 \%)$ patients on the left side. In the mid-clavicular region, the mean (SD) vein cross-sectional area was $1.0(0.5) \mathrm{cm}^{2}$ on the right and $0.8(0.3) \mathrm{cm}^{2}$ on the left. In the lateral-clavicular region, the mean (SD) of the vein cross-sectional area was $0.9(0.4)$ $\mathrm{cm}^{2}$ on the right and $0.7(0.3) \mathrm{cm}^{2}$ on the left. The mean (SD) of the axillary artery area was $0.6(0.2) \mathrm{cm}^{2}$ and 0.5 $(0.2) \mathrm{cm}^{2}$ on the right and left, respectively, but minimally decreased laterally. The average axillary vein diameter and cross-sectional area were larger on the right side in 103 (69\%) patients and smaller in $30(20 \%)$ patients, and the vessels were of equal size in $17(11 \%)$ patients.

Venous and arterial depth and arteriovenous distance

In the mid-clavicular region, the mean (SD) depth of the axillary vein was $2.3(0.6) \mathrm{cm}$ on the right and $2.4(0.6) \mathrm{cm}$ on the left and did not vary between the mid- and lateralclavicular position. In contrast, the mean (SD) depth of the artery was $3.2(0.6) \mathrm{cm}$ on the right and $3.3(0.6) \mathrm{cm}$ on the left, and it would become almost $0.5 \mathrm{~cm}$ more superficial moving laterally. The arteriovenous distance remained constant at $0.2 \mathrm{~cm}$ on both sides, even laterally. 

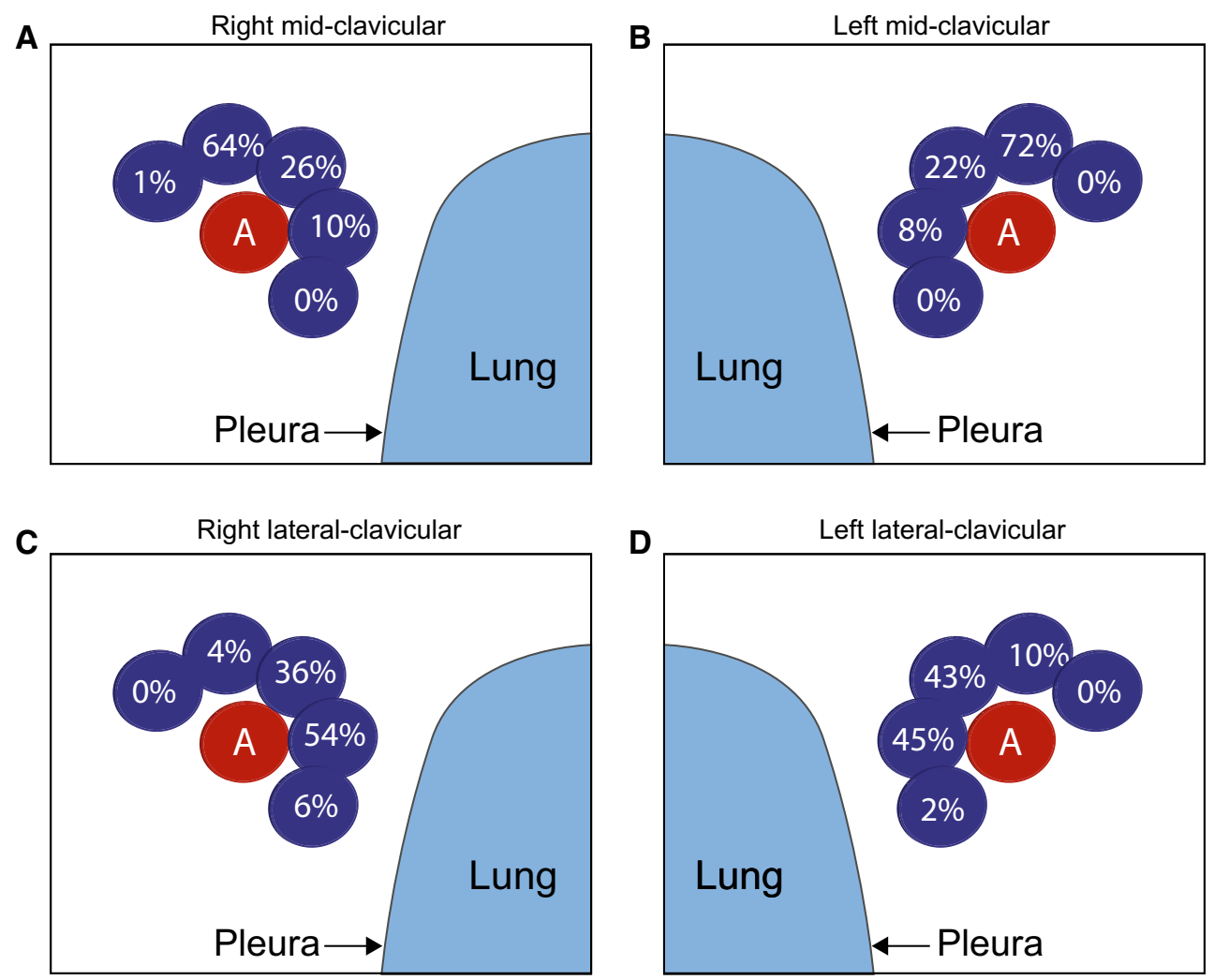

Fig. 4 Position of the vein in relation to the artery. A) Right mid-clavicular, B) left mid-clavicular, C) right lateral-clavicular; and D) left lateralclavicular

Venopleural distance and artery to vein relationship

In the mid-clavicular region, the mean (SD) distance from skin to lung pleura was $3.4(0.8) \mathrm{cm}$ and $3.3(0.6) \mathrm{cm}$ on the right and left side, respectively. The mean (SD) distance between the pleura and the axillary vein was $0.8(0.5) \mathrm{cm}$ and $0.9(0.4) \mathrm{cm}$ on the right and left side, respectively. As the probe moved laterally, this distance did not change significantly. The position of the vein in relation to the artery is shown in Fig. 4. At the mid-clavicular site, the vein was located directly on top of the artery on both the right and left side (position 1 and 2) in $67 \%$ of patients (65\% right and $72 \%$ left) and became medial to the artery (position 3 and 4) in 33\% of patients (36\% right and 30\% left). No axillary veins were observed under the artery. In the lateral-clavicular position, both the right and left axillary veins were medial to the artery in $89 \%$ (90\% right and $88 \%$ left) of patients, and only $7 \%$ of veins ( $4 \%$ right and $10 \%$ left) were directly anterior to the artery. Nevertheless, $4 \%$ of the veins (6\% right and 2\% left) were found to be inferior to the arteries.
Associations, correlations, and models

Overall, females had a significantly smaller mean (SD) vein area than males in all regions: right mid-clavicular region $0.8(0.4) \mathrm{cm}^{2}$ vs $1.1(0.5) \mathrm{cm}^{2}$, respectively $(P=0.002)$; right lateral-clavicular $0.7(0.3) \mathrm{cm}^{2}$ vs 0.9 (0.4) $\mathrm{cm}^{2}$, respectively $(P<0.001)$; left mid-clavicular 0.6 (0.2) $\mathrm{cm}^{2}$ vs $0.9(0.3) \mathrm{cm}^{2}$, respectively $(P<0.001)$; and left lateral-clavicular $0.6(0.2) \mathrm{cm}^{2}$ vs $0.8(0.3) \mathrm{cm}^{2}$, respectively $(P<0.001)$.

The mean (SD) CVP was 14 (4) $\mathrm{mmHg}$, and the systolic and diastolic PAP were 38 (10) $\mathrm{mmHg}$ and 20 (6) $\mathrm{mmHg}$, respectively. There was no correlation between the crosssectional area of the axillary vein and any of the hemodynamic data or filling pressures (all $\mathrm{r}^{2}<0.17$ ). There was a relationship between the depth of the axillary vein and both BMI ( $\mathrm{r}^{2} 0.52$ to $0.6 ; P<0.001$ for all sites) and age $(P=0.018$ and $P<0.001$ for right mid- and lateral-clavicular, respectively; and $P=0.002$ and $P=0.002$ for left mid- and lateral-clavicular, respectively). No significant model could be developed for predicting axillary vein cross-sectional area and depth. 


\section{Discussion}

This study represents an extensive report of US-measured axillary vessel anatomy, and it is novel in its reporting of the relationship between anatomical characteristics and hemodynamic filling pressures. In this study, we obtained images of axillary vessels in the majority of patients using a 10-Mhz US probe and observed clinically relevant anatomical variability. In $97 \%$ of patients, the images were optimal for measurement, even in patients with a BMI as high as $46.4 \mathrm{~kg} \cdot \mathrm{m}^{-2}$. Four patients whose measures were mostly incomplete had an average BMI of $39.0 \mathrm{~kg} \cdot \mathrm{m}^{-2}$ and prominent breast tissue.

Galloway studied 50 patients using a similar approach ${ }^{10}$ and observed axillary vessels in $93 \%$ of the images. They observed that the mean (range) depth from skin to vein increased from $1.9(0.7-3.7) \mathrm{cm}$ medially to 3.1 (1.1-5.6) $\mathrm{cm}$ laterally. The venous diameter was similar to that in the patients in our study but decreased medially in comparison with our population. These differences could be explained by the use of a younger, smaller population with lower BMI. Also, in the Galloway study, the measurement from the vein to the pleura might have been in a more lateral position, which would explain the difference between their measurements and our results. Since the sample size was smaller in the Galloway study, abnormally positioned axillary veins were not identified.

Our observations of anatomical variations in dimension and the relative position of the subclavian/axillary vein to the axillary artery may explain the reported failure rate and complications of cannulation techniques using only surface landmarks and not US. We observed a relatively high percentage of veins that were small $(<1 \mathrm{~cm}$ in diameter) vessels and unfavourably positioned (4\% of arteries were anterior to the vein). Veins $<1 \mathrm{~cm}$ in diameter were present in close to one-third of our patients and would be more difficult to cannulate. ${ }^{16}$ As reported by several authors, the use of US to identify these variations may have helped reduce the number of adverse events and failed cannulations. $^{3,17,18}$

The classic landmark technique of subclavian vein cannulation (i.e., where the needle is inserted below the clavicle and in the direction of the sternal notch) differs from the technique proposed with US. With the use of US, the needle entry point is typically more lateral and aimed directly at the target vessel. In the studies evaluating USguided catheterization, the operators usually used a puncture point located below the clavicle and lateral to the mid-clavicular area. ${ }^{5,6,16}$ Hence, the operator using US technically views and punctures the axillary vein.

Not surprisingly, we observed that the depth of the axillary vein correlates with the BMI, as previously described by Kim et al. ${ }^{11}$ Female patients had a smaller vein area, and age also influenced venous depth and area. Despite these associations, we were unable to obtain a model that could predict the dimension and position of the axillary vessels. These findings support the current interest in using a US-guided vascular approach for axillary/subclavian access. In studies evaluating USguided subclavian vein puncture, vein anatomical anomalies were observed in $2-27 \%$ of the cases. ${ }^{3,10-12}$ Nevertheless, detailed descriptions of these specific arteriovenous anomalies are lacking. Also, our observations partly explain the reported difficulties in using this approach to the central venous system. For example, technical difficulties would be encountered if the axillary vein were to lie under the artery. The use of large catheters (such as those used for dialysis) in patients with small axillary veins may have led to complete occlusion or thrombus after removal. This complication would then preclude subsequent construction of an arteriovenous fistula in the ipsilateral side. In contrast to previous studies of the jugular vein, ${ }^{12}$ CVP and PAP had no correlation with axillary vein dimensions. We speculate that, since the axillary vein is surrounded by numerous fixed structures (i.e., rib cage, pectoralis muscles, cutaneous fat tissue, and clavicle), its size might be influenced by both the surrounding structures and filling pressures rather than by the internal jugular vein which is more superficial and not otherwise contained by the rib cage.

The lateral-clavicular site may be the optimal puncture point as it might decrease complication rates, particularly as the vein does not overlie the artery-despite the fact that the vein is smaller at this location. The size of the vein was smaller in $64 \%$ of patients, but the average difference was $<5 \mathrm{~mm}$ in diameter, and the depth was approximately the same as at the mid-clavicular point. In $>90 \%$ of patients, the vein does not overlap the artery at the lateralclavicular point; thus, the rate of accidental arterial puncture might be reduced. Moreover, the lateral point is an area where external compression could be exerted on the structure, if necessary. In addition, the vein is also further away from the lung pleura, which might decrease the occurrence of pneumothorax. On the other hand, at this site, the brachial plexus surrounds the artery ${ }^{10,11}$ and could be injured, as it is the same site used for infraclavicular nerve block.

\section{Limitations}

Despite efforts being made to ensure uniformity of recording the images, some confounding elements might have been difficult to avoid. Pressure inadvertently applied on the US probe may have reduced the measured depth or the cross-sectional area of the structures. We tried to avoid 
this pitfall and ensure uniformity by having only one operator take all images. We also took precautions to make sure that the structure we were measuring was round or slightly oval. The use of Trendelenburg positioning could have increased the size of the jugular vein ${ }^{19,20}$ and consequently the axillary ${ }^{21}$ veins. Nevertheless, we kept the patient in a neutral position or horizontal at $0^{\circ}$ to ensure the uniformity of the conditions for data collection and also to avoid overestimation of filling pressures because our transducer was attached to the operating room table. Lastly, these images were taken in a specific subpopulation of older cardiac patients often with multiple comorbidities. The results may have differed in more heterogeneous populations in different geographic locations. We did not encounter any thrombosed veins during this study. Thrombosed axillary veins are typically seen in patients with a previous catheter, which was not the case in our patients. Random computed tomography (CT) of the axillary vessels could also have provided us similar information. Nevertheless, the CT would not have been performed with simultaneous central venous catheter insertion; thus, this would have prevented us from measuring and correlating CVP directly with axillary vein anatomy. Indeed, the goal of our study was to assess the anatomy surrounding the axillary vein and not the feasibility of echo-guided subclavian access per se. In a recent study by Vezzani et al. ${ }^{8}$ of 190 patients, the authors observed a $100 \%$ success rate in cannulation when performed by experienced anesthesiologists. In addition, they showed more complications using a long-axis compared to a short-axis approach.

\section{Conclusion}

There is significant anatomical variability in the dimensions and position of the axillary vessels. The axillary vein was in an aberrant position in $4 \%$ of patients. Unlike jugular veins, elevated filling pressures do not appear to impact axillary vein size. Further studies are still needed in order to evaluate the anatomical, demographic, hemodynamic, and anthropometric factors affecting the complication rates of US-guided subclavian central line insertion.

Conflicts of interest and source of funding Dr. Denault is on the Speakers Bureau for Medtronic, Masimo, and CAE Healthcare and supported by the Richard I. Kaufman Endowment Fund in Anesthesia and Critical Care and the Montreal Heart Institute Foundation.

Editorial responsibility This submission was handled by Dr. Hilary P. Grocott, Editor-in-Chief, Canadian Journal of Anesthesia.

\section{References}

1. Hind D, Calvert N, McWilliams $R$, et al. Ultrasonic locating devices for central venous cannulation: meta-analysis. BMJ 2003; 327: 361 .

2. Karakitsos D, Labropoulos N, De Groot E, et al. Real-time ultrasound-guided catheterisation of the internal jugular vein: a prospective comparison with the landmark technique in critical care patients. Crit Care 2006; 10: R162.

3. Fragou M, Gravvanis A, Dimitriou V, et al. Real-time ultrasoundguided subclavian vein cannulation versus the landmark method in critical care patients: a prospective randomized study. Crit Care Med 2011; 39: 1607-12.

4. McGrattan T, Duffty J, Green JS, O'Donnell N. A survey of the use of ultrasound guidance in internal jugular venous cannulation. Anaesthesia 2008; 63: 1222-5.

5. Troianos CA, Kuwik RJ, Pasqual JR, Lim AJ, Odasso DP. Internal jugular vein and carotid artery anatomic relation as determined by ultrasonography. Anesthesiology 1996; 85: 43-8.

6. Gordon AC, Saliken JC, Johns D, Owen R, Gray RR. US-guided puncture of the internal jugular vein: complications and anatomic considerations. J Vasc Interv Radiol 1998; 9: 333-8.

7. Lalu MM, Fayad A, Ahmed $O$, et al. Ultrasound-guided subclavian vein catheterization: a systematic review and metaanalysis. Crit Care Med 2015; 43: 1498-507.

8. Vezzani A, Manca T, Brusasco C, et al. A randomized clinical trial of ultrasound-guided infra-clavicular cannulation of the subclavian vein in cardiac surgical patients: short-axis versus long-axis approach. Intensive Care Med 2017. https://doi.org/10. 1007/s00134-017-4756-6.

9. Senussi MH, Kantamneni PC, Omranian A, et al. Revisiting ultrasound-guided subclavian/axillary vein cannulations: importance of pleural avoidance with rib trajectory. J Intensive Care Med 2017; 32: 396-9.

10. Galloway $S$, Bodenham A. Ultrasound imaging of the axillary vein-anatomical basis for central venous access. Br J Anaesth 2003; 90: 589-95.

11. Kim IS, Kang SS, Park JH, et al. Impact of sex, age and BMI on depth and diameter of the infraclavicular axillary vein when measured by ultrasonography. Eur J Anaesthesiol 2011; 28: 34650.

12. Siva B, Hunt A, Boudville N. The sensitivity and specificity of ultrasound estimation of central venous pressure using the internal jugular vein. J Crit Care 2012; 27: 315.e7-11.

13. von Elm E, Altman DG, Egger M, et al. The Strengthening the Reporting of Observational Studies in Epidemiology (STROBE) statement: guidelines for reporting observational studies. J Clin Epidemiol 2008; 61: 344-9.

14. Schnittger I, Gordon EP, Fitzgerald PJ, Popp RL. Standardized intracardiac measurements of two-dimensional echocardiography. J Am Coll Cardiol 1983; 2: 934-8.

15. Thorpe KE. How to construct regression models for observational studies (and how NOT to do it!). Can J Anesth 2017; 64: 461-70.

16. Sharma A, Bodenham AR, Mallick A. Ultrasound-guided infraclavicular axillary vein cannulation for central venous access. Br J Anaesth 2004; 93: 188-92.

17. Forestier F, Rossi H, Calderon J, Soubiron L, Bourdarias B, Janvier $G$. Training for adult subclavian venous catheterization: use of real-time echography (French). Ann Fr Anesth Reanim 2002; 21: 698-702.

18. Froehlich CD, Rigby MR, Rosenberg ES, et al. Ultrasoundguided central venous catheter placement decreases complications and decreases placement attempts compared with the landmark technique in patients in a pediatric intensive care unit. Crit Care Med 2009; 37: 1090-6. 
19. Marcus HE, Bonkat E, Dagtekin O, et al. The impact of Trendelenburg position and positive end-expiratory pressure on the internal jugular cross-sectional area. Anesth Analg 2010; 111: 432-6.

20. Kim HY, Choi JM, Lee YH, Lee S, Yoo H, Gwak M. Effects of the Trendelenburg position and positive end-expiratory pressure on the internal jugular vein cross-sectional area in children with simple congenital heart defects. Medicine (Baltimore) 2016; 95: e3525.
21. Fortune JB, Feustel P. Effect of patient position on size and location of the subclavian vein for percutaneous puncture. Arch Surg 2003; 138: 996-1000; discussion 1001.

22. Denault AY, Vegas A, Lamarche Y, Tardif JC, Couture P. Basic Transesophageal and Critical Care Ultrasonography. London: CRC Press; 2017. 